\title{
PROTECTIVE EFFECTS OF IVABRADINE (ALONE AND COMBINED WITH ATENOLOL OR ENALAPRIL) ON EXPERIMENTALLY-INDUCED ACUTE MYOCARDIAL INFARCTION IN ALBINO RATS
}

\author{
Shireen Sami Mahmoud, Mohamed Moustafa Shehata, Ali Abd El-Rahman Moustafa, Gehane \\ Ahmed El-Gendy \\ Clinical Pharmacology Departments; Faculty of Medicine; Zagazig University
}

\author{
Corresponding author: \\ Shireen Sami \\ Mahmoud; Tel: \\ 01004386751 ; \\ E-mail: \\ shsothman@gmail.com
}

\begin{abstract}
Background: Cardiovascular disease (CVD) is the leading cause of death worldwide. Deaths are mostly attributable to coronary artery disease (CAD). Ivabradine, a pure heart rate lowering agent, acts by inhibiting the pacemaker $I_{\mathrm{f}}$ current in the sinoatrial node. It can be used for treatment of heart failure and stable angina with the main drugs for CVD.
\end{abstract}

Objectives: To determine the cardioprotective effects of ivabradine pretreatment alone and in combination with each of atenolol and enalapril on acute myocardial infarction (MI) in rats.

Materials \& Methods: Eighty four rats were divided into seven groups (12 rats each): Group 1: sham-operated group; Group 2: control (untreated) MI group; Group 3: ivabradine-pretreated group; Group 4: atenolol-pretreated group; Group 5: enalaprilpretreated group; Group 6: ivabradine and atenolol-pretreated group; and Group 7: ivabradine and enalapril-pretreated group. Rats received drugs orally by gavage daily for 6 days. On the sixth day, acute MI was induced by persistent complete left coronary artery ligation. The parameters studied were mean arterial blood pressure, ECG changes (heart rate, ST height and T-wave voltage), serum levels of creatine kinase MB isoenzyme (CK-MB), cardiac troponin-I (cTnI), high-sensitivity Creactive protein (hs-CRP) and N-terminal pro-brain-type natriuretic peptide (NTproBNP), tissue levels of superoxide dismutase (SOD), reduced glutathione (GSH), Bcl-2-associated X protein (Bax) and the \% of infarct size of the left ventricle.

Results: Coronary artery ligation resulted in significant elevation in ST height, Twave voltage, serum levels of CK-MB, cTnI, hs-CRP and NT-proBNP and tissue levels of Bax, with significant reduction of the tissue levels of SOD \& GSH and produced $54 \%$ infarct size of the left ventricle. Oral pretreatment with ivabradine has cardioprotective effect against acute MI as evidenced by significantly lower ST height, T-wave voltage, serum levels of CK-MB, cTnI, hs-CRP and NT-proBNP and tissue levels of Bax, with significantly higher tissue levels of SOD \& GSH and significantly lower infarct size (into 39\%). Oral pretreatment with combination of ivabradine and atenolol produced greater cardioprotection against acute MI than observed with ivabradine alone evidenced by significantly lower ST height, T-wave voltage, serum levels of CK-MB, cTnI, hs-CRP and NT-proBNP and tissue level of Bax, with significantly higher tissue levels of SOD \& GSH and significantly lower infarct size (into 23\%). Although, the effects of oral pretreatment with combination of ivabradine and enalapril on ST height, T-wave voltage, tissue levels of SOD \& GSH and $\%$ of infarct size were not significantly different from that of ivabradine; however, this combination caused significant reduction of serum levels of CK-MB, cTnI, hs-CRP and NT-proBNP and tissue level of Bax as compared to the effect of ivabradine alone.

Conclusion: Ivabradine possesses protective effects against acute MI and these effects are lower than the protective effects of atenolol; but higher than that of enalapril. Concomitant administration of ivabradine with either atenolol or enalapril provides greater cardioprotection against acute MI than ivabradine alone and these effects are greatest when ivabradine is combined with atenolol.

Keywords: cardiovascular disease, acute coronary syndrome, myocardial infarction, $I_{\mathrm{f}}$ current, ivabradine, atenolol, enalapril

\section{INTRODUCTION} ardiovascular disease (CVD) is the leading cause of death worldwide, which are mostly attributable to coronary artery disease $(\mathrm{CAD})^{[1]}$. Acute coronary syndrome (ACS) describes the myocardial ischemic 
conditions that include unstable angina, nonST-elevation myocardial infarction (NSTEMI) and ST-elevation myocardial infarction (STEMI) [2]. Despite recent advances in the management of patients with $\mathrm{CAD}$, there is a need to decrease deaths due to myocardial infarction (MI) and to improve the patient's quality of life ${ }^{[3]}$.

Heart rate (HR) is a major determinant of myocardial oxygen demand and supply ${ }^{[4]}$. A high resting $\mathrm{HR}$ is associated with increased cardiovascular and total mortality in the general population, as well as in patients with CAD and chronic heart failure "HF" [5].

Reducing resting HR has, therefore, become an important goal in the treatment of patients with CVD. HR-reducing agents used in preventing or treating myocardial ischemia such as $\beta$-blockers and non-dihydropyridine calcium channel blockers (NDHPCCBs) are associated with depression of cardiac contractility, in addition to the difficulty of up-titration to target doses of these drugs ${ }^{[6,7]}$.

These disadvantages have prompted the development of pure HR-reducing agents such as ivabradine ${ }^{[8]}$. Ivabradine provides pure HR reduction by directly and selectively inhibiting the pacemaker $I_{\mathrm{f}}$ current in the sinoatrial node ${ }^{[9]}$. It has no effect on cardiac contractility, repolarization and atrioventricular conduction ${ }^{[10]}$.

Ivabradine protects the myocardium during ischemia and improves cardiovascular outcome in patients with CAD, HF and left ventricular (LV) dysfunction ${ }^{[11]}$. Ivabradine is safe, well tolerated and can be used in combination with the main drugs for $\mathrm{CVD}^{[4]}$. It has been approved for clinical use for HR control in HF and stable angina ${ }^{[12]}$.

The present work is designed to: (1) determine the effects of administration of ivabradine on some parameters of acute MI [mean arterial blood pressure (MABP), electrocardiogram (ECG), cardiac biomarkers and \% of infarct size]; and (2) detect the effects of combination of ivabradine with each of atenolol and enalapril on these parameters.

\subsection{Animals:}

The experiments were conducted on a total of 84 adult male Wister albino rats of weighing 200-250 gm purchased from the animal house of Faculty of Veterinary Medicine, Zagazig University, Egypt. All experiments in this study were performed in accordance with the guidelines for Animal Research from the National Research Center, Cairo, Egypt. The study protocol was approved by the ethical committee of Zagazig University. The rats received a standard diet and water ad labitum and were kept under standard humidity with 12 hours light/dark cycle in plastic cages with wood shave bedding, each cage containing 6 rats.

\subsection{Experimental design:}

The rats were randomly selected and allocated into the following seven experimental groups ( $\mathrm{n}=12$ in each group): Group 1: sham-operated control group; Group 2: control MI group, in which acute MI was induced by coronary artery ligation in untreated rats; Group 3: ivabradine-pretreated group, in which rats were received ivabradine (Servier, Courbevoie, France) in a dose of 10 $\mathrm{mg} / \mathrm{kg} /$ day ${ }^{[13]}$; Group 4: atenolol-pretreated group in which rats were received atenolol (St. Louis, MO, USA) in a dose of 6 $\mathrm{mg} / \mathrm{kg} /$ day ${ }^{[14]}$; Group 5: enalapril-pretreated group, in which rats were received enalapril (El Haram, Giza, Egypt) in a dose of 1 $\mathrm{mg} / \mathrm{kg} /$ day ${ }^{[15]}$; Group 6: the ivabradine and atenolol-pretreated group, in which rats were received combination of ivabradine and atenolol; and Group 7: ivabradine and enalapril-pretreated group in which rats were received combination of ivabradine and enalapril. The animals of groups 1 and 2 received distilled water, $1 \mathrm{ml} / 100 \mathrm{gm}$ rat daily, orally by gavage for 6 days. Animals of the pretreated category (groups 3 to 7 ) received drugs orally once daily for 6 days then coronary ligation was done 2 hours after the last dose on the sixth day.

\subsection{Induction of acute MI by coronary} artery ligation:

The rats were anesthetized with urethane (Prolabo, Paris, France) in a dose of 1.75-2 gram/kg injected intraperitoneally ${ }^{[16]}$. Tracheotomy was done and an endotracheal tube was connected to the artificial ventilator. 
The thorax was opened to exteriorize the heart and ligation of the proximal left anterior descending coronary artery about $2-3 \mathrm{~mm}$ from its origin with 6-0 silk suture was done. The heart was returned to its normal position then thorax was closed. Sham-operated rats underwent the identical surgical procedure as described above except ligation of the coronary artery ${ }^{[17]}$.

\subsection{Hemodynamic parameters:}

The carotid artery was cannulated to measure arterial blood pressure with a pressure transducer. Lead II ECG was monitored via subcutaneous stainless-steel needle electrodes. ECG parameters measured include heart rate $(\mathrm{b} / \mathrm{m})$, ST height $(\mathrm{mV})$ and T-wave voltage $(\mathrm{mV})$. MABP and ECG were recorded before coronary artery ligation, immediately after ligation and every 30 minutes for 6 hours after coronary ligation. We used PowerLab (4/35) data acquisition system (ADInstruments, Castle Hill, Australia, Pty Ltd.) for MABP and ECG monitoring. Data were extracted and analyzed by LabChart7 software before and 4 hours after coronary ligation.

\subsection{Biochemical studies:}

1.5.1. Measurements of serum CK-MB, cTnI, hs-CRP and NT-proBNP levels:

At the end of each experiment (6 hours after coronary artery ligation), blood samples were collected in clean dry test tubes from rat arterial polyethylene cannula, centrifuged at $3000 \mathrm{rpm}$ for 15 minutes. Serum was collected and stored at $-20^{\circ} \mathrm{c}$ as aliquots for biochemical determination of serum levels of CK-MB, cTnI, hs-CRP and NT-proBNP by enzyme-linked immunosorbent assay (ELISA) by using diagnostic kits for CK-MB (Bioassay technology laboratory, Shanghai Crystal Day Biotech CO., LTD), cTnI (Kamiya Biomedical Company, Seattle, USA), hs-CRP (Wuhan EIAab Science CO., LTD, Wuhan, China) and NT-proBNP (MESO Scale Discovery, Gaithersburg, USA) according to the manufacturer's instructions.

\subsubsection{Measurements of tissue SOD, GSH and Bax levels:}

Hearts of six rats in each group were excised and rinsed thoroughly with saline, froze by liquid nitrogen and then stored at - $80^{\circ} \mathrm{C}$ for biochemical determinations of the tissue levels of SOD, GSH and Bax by ELISA by using diagnostic kits for SOD (Cell Biolabs, Inc. San Diego, USA), GSH (Oxford Biomedical Research., Oxford, USA) and Bax (Wuhan EIAab Science CO., LTD, Wuhan, China) according to the manufacturer's instructions.

\subsection{Measurement of infarct size:}

At the end of each experiment, the beating hearts of six rats in each group were excised and submerged in normal saline solution. Fine dissection was done freeing the heart from adjacent tissues and big vessels then each heart was sectioned into three 1.5-2 $\mathrm{mm}$ transverse slices from the level of the ligation to the apex. The slices were then incubated in a $1.5 \%$ Triphenyl-Tetrazolium Chloride (TTC) in phosphate buffer $\mathrm{pH} 7.4$, for $15-20$ minutes at $37^{\circ} \mathrm{C}$. The non-infarcted tissue stained crimson red, while the area of necrosis that lack dehydrogenase activity remained pale ${ }^{[\mathbf{1 8}]}$.

Once the color has been established, place clear glass plates over the both sides of slices. Then the tissues were photographed using a digital camera. The areas of infarction are determined by planimetry, using a validated image analysis program; the UTHSCSA Image Tool "ITOOL" version 2.00 (developed at the University of Texas Health Science Center at San Antonio, Texas, USA) ${ }^{[19]}$. The infarction size ratio was defined as the area of the infarct divided by the total left ventricle area and expressed as a percentage ${ }^{[20]}$.

\subsection{Statistical analysis:}

The data were expressed as mean \pm standard error of mean (SE). The data were statistically analyzed by one-way analysis of variance (ANOVA) followed by post hoc Tukey test as described by Armitage and Berry ${ }^{\text {[21] }}$. Values of $p<0.05$ were considered significant. GraphPad Prism version 5.00 for Windows (GraphPad Software, San Diego California; USA) was used to carry out the statistical analysis.

\section{RESULTS}

\section{8. $\quad \mathrm{MABP}(\mathrm{mmHg})$ : (Tab. 1)}

The basal (before coronary artery ligation) MABP was $97 \pm 2.856 \mathrm{mmHg}$ in the 
control MI group which was significantly $(\mathrm{p}<0.05)$ decreased to $78 \pm 3.336 \mathrm{mmHg} 4$ hours after coronary artery ligation. Also, the later value was significantly $(p<0.05)$ lower than that of the sham-operated group $(89 \pm 2.939 \mathrm{mmHg})$. In the pretreated groups by ivabradine, atenolol, enalapril, ivabradine \& atenolol and ivabradine \& enalapril the basal MABP values were $90 \pm 2.520$, $89 \pm 2.298,86 \pm 2.141,86 \pm 2.028$ and $83 \pm 1.976$ $\mathrm{mmHg}$ respectively. The MABP values recorded 4 hours after the operation for the above pretreated groups were $85 \pm 2.985,82 \pm$ $2.634,77 \pm 2.649,78 \pm 3.170$ and $76 \pm 2.494$ $\mathrm{mmHg}$ respectively, which were not significantly different from their basal values. In addition, the MABP values recorded 4 hours after the operation for the ivabradinepretreated and atenolol-pretreated groups were not significantly different from that of the sham-operated group. These findings could give evidence that all pretreatments could attenuate the hypotension caused by MI. However, the MABP values recorded 4 hours after the operation for ivabradine and atenolol-pretreated and ivabradine and enalapril-pretreated groups were significantly $(p<0.05)$ lower than that of the sham-operated group.

\subsection{Heart Rate (b/m): (Tab. 1)}

The baseline values of HR of shamoperated, control MI and enalapril-pretreated groups were $312 \pm 7.341,308 \pm 7.388$ and $320 \pm 8.119 \mathrm{~b} / \mathrm{m}$ respectively, which were not significantly different from each others. In comparison with the fore-mentioned groups, significant $(\mathrm{p}<0.05)$ lower HR was recorded with groups pretreated by ivabradine (253 \pm 6.803$), \quad$ atenolol $(265 \pm 6.847)$, ivabradine \& atenolol $(219 \pm 7.412)$ and ivabradine \& enalapril $(257 \pm 7.115 \mathrm{~b} / \mathrm{m})$. In addition, significant $(\mathrm{p}<0.05)$ lower HR was recorded in ivabradine and atenolol-pretreated group in comparison to that of either ivabradine or atenolol. On the other hand, the HR in ivabradine and enalapril-pretreated group was not significantly different from that of ivabradine-pretreated group.

Values of HR recorded 4 hours after coronary artery ligation in control $\mathrm{MI}$ and enalapril-pretreated groups were $381 \pm 10.720$ and $362 \pm 8.628 \mathrm{~b} / \mathrm{m}$ respectively, which were not significantly different from each other, but significantly $(p<0.05)$ higher than the baseline value and that of the sham-operated group. In comparison to former two groups; significant $(\mathrm{p}<0.05)$ lower HR values were recorded in groups pretreated with ivabradine (307 \pm 13.920$)$ atenolol $(291 \pm 12.750)$, ivabradine \& atenolol $(238 \pm 10.150)$ and ivabradine \& enalapril $(309 \pm 9.601 \mathrm{~b} / \mathrm{m})$. In the meantime, the HR value of the ivabradine and atenolol-pretreated group was significantly $(\mathrm{p}<0.05)$ lower than that of all other pretreated groups.

\subsection{ST height (mV): (Tab. 2)}

Values ST height recorded 4 hours after coronary artery ligation in all groups were significantly $(\mathrm{p}<0.05)$ increased as compared to either the baseline value of each group or that of the sham operated group.

The ST height values recorded 4 hours after coronary artery ligation in control MI and enalapril-pretreated groups were $0.207 \pm 0.011$ and $0.187 \pm 0.006 \mathrm{mV}$ respectively. In comparison with the two later groups, significant $(\mathrm{p}<0.05)$ lower values were recorded in groups pretreated with ivabradine $\quad(0.170 \pm 0.006), \quad$ atenolol $(0.141 \pm 0.007), \quad$ ivabradine \& atenolol $(0.126 \pm 0.004)$ and ivabradine \& enalapril $(0.155 \pm 0.009 \mathrm{mV})$. In addition, this value in the ivabradine and atenolol-pretreated group was significantly $(p<0.05)$ lower than that of the ivabradine-pretreated group.

\subsection{T-wave voltage $(\mathrm{mV})$ : (Tab. 2$)$}

Values of T-wave voltage recorded 4 hours after coronary artery ligation were significantly $(p<0.05)$ increased in all groups in comparison to either the baseline value of each group or that of the sham operated group..

The T-wave voltage values recorded 4 hours after coronary artery ligation in the control MI group was $0.271 \pm 0.015 \mathrm{mV}$. In comparison to the later, significant $(\mathrm{p}<0.05)$ lower values were recorded in groups pretreated with ivabradine $(0.187 \pm 0.008)$, atenolol $\quad(0.160 \pm 0.010), \quad$ enalapril $(0.195 \pm 0.009), \quad$ ivabradine \& atenolol $(0.142 \pm 0.007)$ and ivabradine \& enalapril$(0.174 \pm 0.007 \mathrm{mV})$. Furthermore this value in 
the ivabradine and atenolol-pretreated group was significantly $(\mathrm{p}<0.05)$ lower than that pretreated with either ivabradine or enalapril.

\subsection{Biochemical Results:}

1.12.1. Effects of different treatments on the serum CK-MB level: (Tab. 3)

The serum levels of CK-MB in the control MI group was $17.910 \pm 0.676 \mathrm{ng} / \mathrm{ml}$, which was significantly $(\mathrm{p}<0.05)$ higher than that of the sham-operated group $(1.275 \pm 0.116$ $\mathrm{ng} / \mathrm{ml}$ ). In comparison to the control MI group, significant $(\mathrm{p}<0.05)$ lower levels of CK-MB were detected in groups pretreated with ivabradine $(7.300 \pm 0.288)$, atenolol (3.650 \pm 0.273$)$, enalapril $\quad(9.888 \pm 0.338)$, ivabradine \& atenolol $(2.488 \pm 0.147)$ and ivabradine \& enalapril $(5.163 \pm 0.209) \mathrm{ng} / \mathrm{ml}$. Interestingly, the enzyme level in the ivabradine and atenolol-pretreated group was not significantly different from that of the sham-operated group.

1.12.2. Effects of different treatments on the serum cTnI levels: (Tab. 3)

The serum levels of cTnI in the control MI group was $4.77 \pm 0.174 \mathrm{ng} / \mathrm{ml}$, which was significantly $(p<0.05)$ higher than that of the sham-operated group $(0.339 \pm 0.029 \mathrm{ng} / \mathrm{ml})$. In groups of rats pretreated with ivabradine, atenolol, enalapril, ivabradine \& atenolol and ivabradine \& enalapril, the cTnI levels were $2.399 \pm 0.218, \quad 1.330 \pm 0.122, \quad 3.061 \pm 0.191$, $0.951 \pm 0.049$ and $1.694 \pm 0.136 \mathrm{ng} / \mathrm{ml}$ respectively, which were significantly $(\mathrm{p}<0.05)$ lower than that of the control MI group. In addition, cTnI level in the ivabradine and atenolol-pretreated group was not significantly different from that of the sham-operated group.

1.12.3. Effects on the serum hs-CRP level: (Tab. 3)

The serum levels of hs-CRP in the control MI group was $16.310 \pm 0.529 \mathrm{ng} / \mathrm{ml}$, which was significantly $(\mathrm{p}<0.05)$ higher than that of the sham-operated group $(1.171 \pm 0.053$ $\mathrm{ng} / \mathrm{ml}$ ). In groups of rats pretreated with ivabradine, atenolol, enalapril, ivabradine \& atenolol and ivabradine \& enalapril, the hsCRP levels were $6.640 \pm 0.290,2.539 \pm 0.205$, $8.500 \pm 0.296,1.630 \pm 0.060$ and $4.430 \pm 0.1191$ $\mathrm{ng} / \mathrm{ml}$ respectively, which were significantly $(p<0.05)$ lower than that of the control MI group. In addition, hs-CRP level in the ivabradine and atenolol-pretreated group was not significantly different from that of the sham-operated group.

\subsubsection{Effects on the serum NT-proBNP level: (Tab. 3)}

The serum levels of NT-proBNP in the control MI group was $202 \pm 6.234 \mathrm{pg} / \mathrm{ml}$, which was significantly $(\mathrm{p}<0.05)$ higher than that of the sham-operated group $(25 \pm 1.745$ $\mathrm{pg} / \mathrm{ml})$. In comparison to the control MI group, significant $(\mathrm{p}<0.05)$ lower levels of the enzyme were detected in groups pretreated with ivabradine $(89 \pm 4.040)$, atenolol (49 \pm 2.070$)$, enalapril (119 \pm 2.815$)$, ivabradine $\&$ atenolol $(39 \pm 1.460)$ and ivabradine \& enalapril $(63 \pm 2.797) \mathrm{pg} / \mathrm{ml}$. Furthermore, the NT-proBNP level in the ivabradine and atenolol-pretreated group was not significantly different from that of the shamoperated group.

\subsubsection{Effects on the cardiac tissue SOD} levels: (Tab. 4)

The cardiac tissue levels of SOD in the control MI group was $1.408 \pm 0.166 \mathrm{U} / \mathrm{g}$ tissue, which was significantly $(\mathrm{p}<0.05)$ lower than that of the sham-operated group $7.925 \pm 0.319$ $\mathrm{U} / \mathrm{g}$ tissue. In groups of animals pretreated with ivabradine, atenolol, enalapril, ivabradine \& atenolol and ivabradine \& enalapril, the SOD levels were 4.256 \pm 0.160 , $5.656 \pm 0.156,3.140 \pm 0.198,6.320 \pm 0.197$ and $5.120 \pm 0.207 \mathrm{U} / \mathrm{g}$ tissue respectively, which were significantly $(\mathrm{p}<0.05)$ higher than that of the control MI group. However, the enzyme levels in all pretreated groups were still significantly $(\mathrm{p}<0.05)$ lower than that of the sham-operated group.

\subsubsection{Effects on the cardiac tissue GSH} levels: (Tab. 4)

The cardiac tissue levels of GSH in the control MI group was $0.742 \pm 0.057 \mu \mathrm{mol} / \mathrm{g}$ tissue, which was significantly $(\mathrm{p}<0.05)$ lower than that of the sham-operated group $(4.066 \pm 0.160 \mu \mathrm{mol} / \mathrm{g}$ tissue). In comparison to the control MI group, significant $(p<0.05)$ higher levels of the enzyme were detected in groups pretreated with ivabradine (1.747 \pm 0.108$), \quad$ atenolol $\quad(2.630 \pm 0.117)$, enalapril $(1.327 \pm 0.0822)$, ivabradine \& atenolol (3.103 \pm 0.103$)$ and ivabradine \& 
enalapril $\quad(2.074 \pm 0.088) \quad \mu \mathrm{mol} / \mathrm{g} \quad$ tissue respectively. However, the GSH values in all pretreated groups were still significantly $(p<0.05)$ lower than that of the sham-operated group.

1.12.7. Effects on the cardiac tissue Bax levels: (Tab. 4)

The cardiac tissue levels of Bax in the control MI group was 26.08 $\pm 0.952 \mathrm{ng} / \mathrm{g}$ tissue, which was significantly $(\mathrm{p}<0.05)$ higher than that of the sham-operated group $(3.743 \pm 0.241 \mathrm{ng} / \mathrm{g}$ tissue). In comparison to the control MI group, significant $(\mathrm{p}<0.05)$ lower levels of the enzyme were detected in groups pretreated with ivabradine (15.63 \pm 0.718$), \quad$ atenolol $\quad(9.26 \pm 0.621)$, enalapril $(19.87 \pm 0.845)$, ivabradine \& atenolol $(6.59 \pm 0.283)$ and ivabradine \& enalapril (12.44 \pm 0.491$) \mathrm{ng} / \mathrm{g}$ tissue. In addition, the Bax tissue level in the ivabradine and atenolol-pretreated group was not significantly different from that of the shamoperated group.

1.13. Effects on infarct size of left ventricle: (Tab. 5; Photo. 1)

The estimated value of infarct size \% of the left ventricle in the control MI group was
$54 \pm 1.676 \%$; while no infarction could be detected in the sham-operated group. In the groups of rats pretreated with ivabradine, atenolol, enalapril, ivabradine $\&$ atenolol and ivabradine \& enalapril the infarct size values were $39 \pm 1.836, \quad 32 \pm 1.290, \quad 44 \pm 1.614$, $23 \pm 1.675$ and $37 \pm 1.252 \%$ respectively, which were significantly $(\mathrm{p}<0.05)$ lower than that of the control MI group.

As demonstrated in table (5), the \% of infarct size in group of rats pretreated with atenolol was significantly $(p<0.05)$ lower than that of either ivabradine or enalapril and that of ivabradine was significantly $(\mathrm{p}<0.05)$ lower than that of enalapril.

In the interaction experiments the $\%$ of infarct size in group of rats pretreated with ivabradine and atenolol was significantly $(\mathrm{p}<0.05)$ lower than that of either ivabradine or atenolol, demonstrating a potentiation between the two drugs on this parameter, on the other hand, the $\%$ of infarct size in group of rats pretreated with combination of ivabradine and enalapril was not significantly different from that of ivabradine; demonstrating no interaction between the two drugs on this parameter.

Table 1: The changes (mean $\pm \mathrm{SE})$ of MABP $(\mathrm{mmHg})$ and HR $(\mathrm{b} / \mathrm{m})$ in different groups:

\begin{tabular}{|c|c|c|c|c|}
\hline Parameter & \multicolumn{2}{|c|}{ МАВP } & \multicolumn{2}{|c|}{ HR } \\
\hline Groups Interval & Baseline & $\begin{array}{l}4 \text { hours after } \\
\text { operation }\end{array}$ & Baseline & $\begin{array}{l}4 \text { hours after } \\
\text { operation }\end{array}$ \\
\hline Sham-operated & $98 \pm 2.800^{\mathbf{A}[\mathbf{a}]}$ & $89 \pm 2.939^{\mathrm{A}[\mathrm{a}]}$ & $312 \pm 7.341^{\mathrm{A}[\mathrm{a}]}$ & $313 \pm 13.490^{\mathbf{A}[\mathbf{a}]}$ \\
\hline Control MI & $97 \pm 2.856^{\mathrm{A}[\mathrm{a}]}$ & $78 \pm 3.336^{\mathbf{B}[\mathbf{b}]}$ & $308 \pm 7.388^{\mathbf{A}[\mathbf{a}]}$ & $381 \pm 10.720^{\mathbf{B}[\mathbf{b}]}$ \\
\hline Ivabradine-pretreated & $90 \pm 2.520^{\mathbf{A}, \mathbf{B}[\mathbf{a}]}$ & $85 \pm 2.985^{\mathbf{A , B}[\mathbf{a}]}$ & $253 \pm 6.803^{\text {B [a] }}$ & $307 \pm 13.920^{\mathbf{A}[\mathbf{b}]}$ \\
\hline Atenolol-pretreated & $89 \pm 2.298^{\mathbf{A}, \mathbf{B}[\mathbf{a}]}$ & $82 \pm 2.634^{\mathrm{A}, \mathrm{B}[\mathrm{a}]}$ & $265 \pm 6.847^{\text {B [a] }}$ & $291 \pm 12.750^{\mathbf{A}[\mathbf{a}]}$ \\
\hline Enalapril-pretreated & $86 \pm 2.141^{\mathrm{B}[\mathrm{a}]}$ & $77 \pm 2.649^{\mathbf{B}[a]}$ & $320 \pm 8.119^{\mathrm{A}[\mathrm{a}]}$ & $362 \pm 8.628^{\mathbf{B}[\mathbf{b}]}$ \\
\hline $\begin{array}{l}\text { Ivabradine and Atenolol- } \\
\text { pretreated }\end{array}$ & $86 \pm 2.028^{\mathbf{B}[a]}$ & $78 \pm 3.170^{\mathbf{B}[\mathbf{a}]}$ & $219 \pm 7.412^{\mathrm{C}[\mathrm{a}]}$ & $238 \pm 10.150^{\mathrm{C}[\mathrm{a}]}$ \\
\hline $\begin{array}{l}\text { Ivabradine and } \\
\text { Enalapril-pretreated }\end{array}$ & $83 \pm 1.976^{\mathbf{B}[a]}$ & $76 \pm 2.494^{\mathbf{B}[\mathbf{a}]}$ & $257 \pm 7.115^{\mathrm{B}[\mathrm{a}]}$ & $309 \pm 9.601^{\mathbf{A}[\mathbf{b}]}$ \\
\hline
\end{tabular}

Number of animals $=12$ rats in each group.

Within the same column, values without common superscript capital letters are significantly different $(\mathrm{p}<0.05)$.

Within the same row, values without common superscript small letters are significantly different $(\mathrm{p}<0.05)$. 
Table 2: The changes (mean \pm SE) of the ST height $(\mathrm{mV})$ and T-wave voltage $(\mathrm{mV})$ in different groups:

\begin{tabular}{|c|c|c|c|c|}
\hline Parameter & \multicolumn{2}{|c|}{ ST height } & \multicolumn{2}{|c|}{ T-wave voltage } \\
\hline $\begin{array}{ll}\text { Groups } & \text { Interval } \\
\end{array}$ & Baseline & $\begin{array}{c}4 \text { hours after } \\
\text { operation }\end{array}$ & Baseline & $\begin{array}{c}4 \text { hours after } \\
\text { operation }\end{array}$ \\
\hline Sham-operated & $-0.0404 \pm 0.004^{\mathbf{A}[\mathrm{a}]}$ & $-0.033 \pm 0.002^{\mathbf{A}[\mathrm{a}]}$ & $0.062 \pm 0.006^{\mathbf{A}[\mathrm{a}]}$ & $0.056 \pm 0.004^{\mathrm{A}[\mathrm{a}]}$ \\
\hline Control MI & $-0.041 \pm 0.004^{\mathrm{A}[\mathrm{a}]}$ & $0.207 \pm 0.011^{\mathbf{B}[\mathbf{b}]}$ & $0.071 \pm 0.004^{\mathrm{A}[\mathrm{a}]}$ & $0.271 \pm 0.015^{\mathbf{B}[\mathbf{b}]}$ \\
\hline Ivabradine-pretreated & $-0.0313 \pm 0.003^{\mathrm{A}[\mathrm{a}]}$ & $0.170 \pm 0.006^{\mathbf{C}[\mathbf{b}]}$ & $0.067 \pm 0.004^{\mathrm{A}[\mathrm{a}]}$ & $0.187 \pm 0.008^{\mathrm{C}[\mathbf{b}]}$ \\
\hline Atenolol-pretreated & $-0.0325 \pm 0.003^{\mathrm{A}[\mathrm{a}]}$ & $0.141 \pm 0.007^{\mathbf{C}, \mathbf{D}[\mathbf{b}]}$ & $0.070 \pm 0.007^{\mathrm{A}[\mathrm{a}]}$ & $0.160 \pm 0.010^{\mathbf{C}, \mathbf{D}[\mathbf{b}]}$ \\
\hline Enalapril-pretreated & $-0.0316 \pm 0.003^{\mathrm{A}[\mathrm{a}]}$ & $0.187 \pm 0.006^{\mathbf{B}[\mathbf{b}]}$ & $0.060 \pm 0.003^{\mathrm{A}[\mathrm{a}]}$ & $0.195 \pm 0.009^{\mathrm{C}[\mathbf{b}]}$ \\
\hline $\begin{array}{l}\text { Ivabradine and } \\
\text { Atenolol-pretreated }\end{array}$ & $-0.0276 \pm 0.002^{\mathrm{A}[\mathrm{a}]}$ & $0.126 \pm 0.004^{\mathbf{D}[\mathbf{b}]}$ & $0.056 \pm 0.005^{\mathrm{A}[\mathrm{a}]}$ & $0.142 \pm 0.007^{\mathbf{D}[\mathbf{b}]}$ \\
\hline $\begin{array}{l}\text { Ivabradine and } \\
\text { Enalapril-pretreated }\end{array}$ & $-0.0329 \pm 0.003^{\mathrm{A}[\mathrm{a}]}$ & $0.155 \pm 0.009^{\mathbf{C , D}[\mathbf{b}]}$ & $0.056 \pm 0.003^{\mathrm{A}[\mathrm{a}]}$ & $0.174 \pm 0.007^{\mathbf{C , D}[\mathbf{b}]}$ \\
\hline
\end{tabular}

Table 3: The serum level (mean \pm SE) of CK-MB, cTnI, hs-CRP and NT-proBNP in the different groups:

\begin{tabular}{|c|c|c|c|c|}
\hline Group $\quad$ Parameter & $\begin{array}{c}\text { Serum CK-MB } \\
(\mathrm{ng} / \mathrm{ml})\end{array}$ & $\begin{array}{l}\text { Serum cTnI } \\
(n g / m l)\end{array}$ & $\begin{array}{c}\text { Serum hs-CRP } \\
(\mathrm{ng} / \mathrm{ml})\end{array}$ & $\begin{array}{c}\text { Serum NT-proBNP } \\
(\mathrm{pg} / \mathrm{ml})\end{array}$ \\
\hline Sham-operated & $1.275 \pm 0.116^{\mathrm{A}}$ & $0.339 \pm 0.029^{\mathbf{A}}$ & $1.171 \pm 0.053^{\mathrm{A}}$ & $25 \pm 1.745^{\mathrm{A}}$ \\
\hline Control MI & $17.910 \pm 0.676^{\mathbf{B}}$ & $4.770 \pm 0.174^{\mathbf{B}}$ & $16.310 \pm 0.529^{\mathbf{B}}$ & $202 \pm 6.234^{\mathbf{B}}$ \\
\hline Ivabradine-pretreated & $7.300 \pm 0.288^{\mathrm{C}}$ & $2.399 \pm 0.218^{\mathrm{C}}$ & $6.640 \pm 0.290^{\mathrm{C}}$ & $89 \pm 4.040^{\mathrm{C}}$ \\
\hline Atenolol-pretreated & $3.650 \pm 0.273^{\mathrm{D}, \mathbf{F}}$ & $1.330 \pm 0.122^{\mathbf{D , F}}$ & $2.539 \pm 0.205^{\mathrm{D}}$ & $49 \pm 2.070^{\mathbf{D , F}}$ \\
\hline Enalapril-pretreated & $9.888 \pm 0.338^{\mathbf{E}}$ & $3.061 \pm 0.191^{\mathbf{E}}$ & $8.500 \pm 0.296^{\mathbf{E}}$ & $119 \pm 2.815^{\mathbf{E}}$ \\
\hline $\begin{array}{l}\text { Ivabradine and atenolol- } \\
\text { pretreated }\end{array}$ & $2.488 \pm 0.147^{\mathbf{A}, \mathbf{D}}$ & $0.951 \pm 0.049^{\mathbf{A}, \mathbf{D}}$ & $1.630 \pm 0.060^{\mathbf{A}, \mathbf{D}}$ & $39 \pm 1.460^{\mathbf{A}, \mathbf{D}}$ \\
\hline $\begin{array}{l}\text { Ivabradine and enalapril- } \\
\text { pretreated }\end{array}$ & $5.163 \pm 0.209^{\mathbf{F}}$ & $1.694 \pm 0.136^{\mathbf{F}}$ & $4.430 \pm 0.191^{\mathbf{F}}$ & $63 \pm 2.797^{\mathrm{F}}$ \\
\hline
\end{tabular}

Number of animals $=12$ rats in each group.

Within the same column, values without common superscript capital letters are significantly different $(\mathrm{p}<0.05)$ by ANOVA.

Table 4: The cardiac tissue levels (mean \pm SE) of SOD, GSH and Bax in the different groups of rats:

\begin{tabular}{|l|ccc|}
\hline \multicolumn{1}{|c|}{ Parameter } & $\begin{array}{c}\text { Tissue SOD } \\
\text { (U/g tissue) }\end{array}$ & $\begin{array}{c}\text { Tissue GSH } \\
(\mu \mathrm{mol} / \mathrm{g} \text { tissue })\end{array}$ & $\begin{array}{c}\text { Tissue Bax } \\
(\text { ng/g tissue })\end{array}$ \\
\hline Sham-operated & $7.925 \pm 0.319^{\mathbf{A}}$ & $4.066 \pm 0.160^{\mathbf{A}}$ & $3.743 \pm 0.241^{\mathbf{A}}$ \\
Control MI & $1.408 \pm 0.166^{\mathbf{B}}$ & $0.742 \pm 0.057^{\mathbf{B}}$ & $26.08 \pm 0.952^{\mathbf{B}}$ \\
Ivabradine-pretreated & $4.256 \pm 0.160^{\mathbf{C}}$ & $1.747 \pm 0.108^{\mathbf{C}, \mathbf{F}}$ & $15.63 \pm 0.718^{\mathbf{C}}$ \\
Atenolol-pretreated & $5.656 \pm 0.156^{\mathbf{D}, \mathbf{F}}$ & $2.630 \pm 0.117^{\mathbf{D}}$ & $9.26 \pm 0.621^{\mathbf{D}}$ \\
Enalapril-pretreated & $3.140 \pm 0.198^{\mathbf{E}}$ & $1.327 \pm 0.0822^{\mathbf{C}}$ & $19.87 \pm 0.845^{\mathbf{E}}$ \\
Ivabradine and atenolol-pretreated & $6.320 \pm 0.197^{\mathbf{D}}$ & $3.103 \pm 0.103^{\mathbf{E}}$ & $6.59 \pm 0.283^{\mathbf{A}, \mathbf{D}}$ \\
Ivabradine and enalapril-pretreated & $5.120 \pm 0.207^{\mathbf{C}, \mathbf{F}}$ & $2.074 \pm 0.088^{\mathbf{F}}$ & $12.44 \pm 0.491^{\mathbf{F}}$ \\
\hline
\end{tabular}

Number of animals $=6$ rats in each group.

Within the same column, values without common superscript capital letters are significantly different $(\mathrm{p}<0.05)$ by ANOVA. 
Table 5: The infarct size (\%) of the left ventricle (mean \pm SE) in rats of the different groups:

\begin{tabular}{|l|c|}
\hline \multicolumn{1}{|c|}{ Group } & $\begin{array}{c}\text { Infarct size } \\
(\%)\end{array}$ \\
\hline Sham-operated & $0.00^{\mathbf{A}}$ \\
Control MI & $54 \pm 1.676^{\mathbf{B}}$ \\
Ivabradine-pretreated & $39 \pm 1.836^{\mathbf{C}}$ \\
Atenolol-pretreated & $32 \pm 1.290^{\mathbf{D}}$ \\
Enalapril-pretreated & $44 \pm 1.614^{\mathbf{E}}$ \\
Ivabradine and Atenolol-pretreated & $23 \pm 1.675^{\mathbf{F}}$ \\
Ivabradine and Enalapril-pretreated & $37 \pm 1.252^{\mathrm{C}, \mathrm{D}}$ \\
\hline
\end{tabular}

Number of animals $=6$ rats in each group.

Within the same column, values without common superscript capital letters are significantly different $(p<0.05)$ by ANOVA.

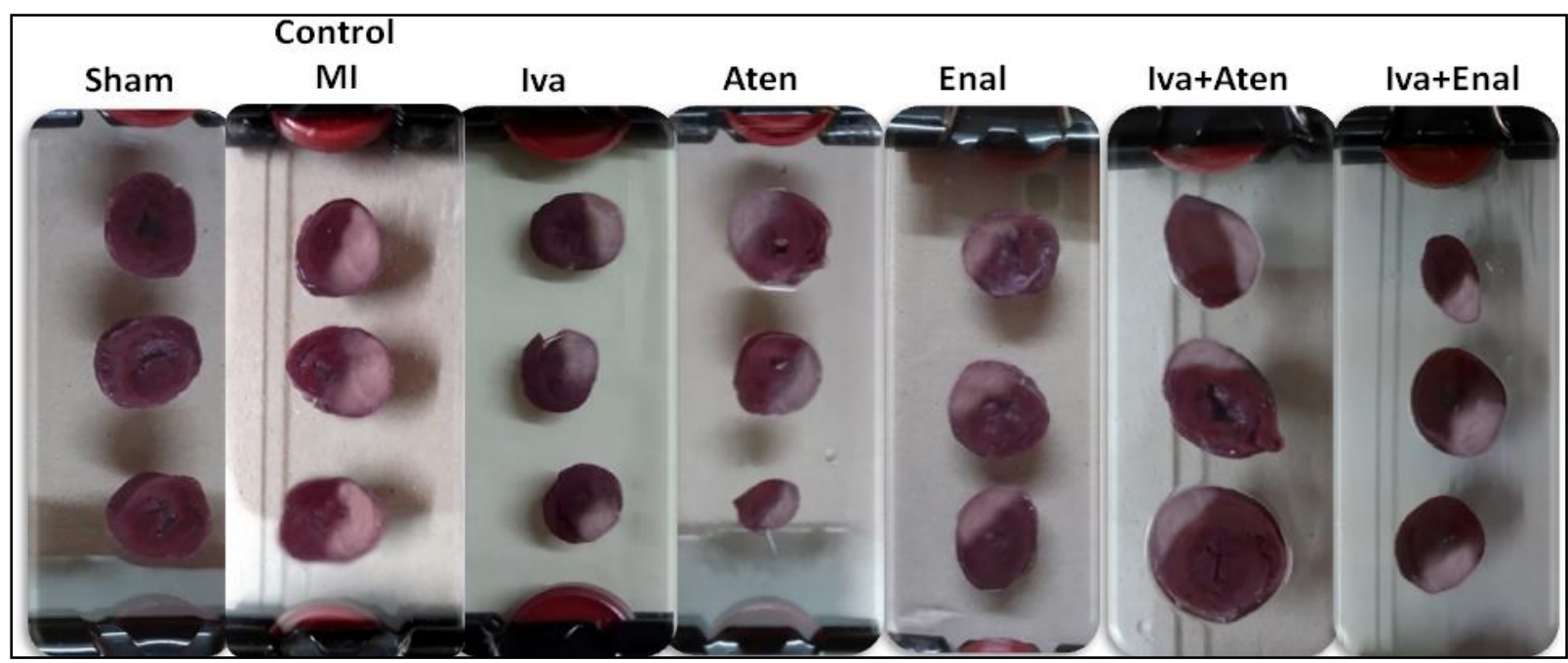

Photo 1: Images of TTC stained cross-section of the rats' hearts showing effects of different treatments on myocardial infarct size after ligation of the left anterior descending coronary artery; Sham: sham-operated group, Control MI: untreated MI group, Iva: ivabradine-pretreated group, Aten: atenolol-pretreated group, Enal: enalapril-pretreated group, Iva+Aten: ivabradine and atenolol-pretreated group, Iva+Enal: ivabradine and enalapril-pretreated group.

\section{DISCUSSION}

The present study demonstrated that ivabradine possesses cardioprotective effects against acute MI induced by persistent coronary artery ligation in rats and these protective effects are lower than that of atenolol and higher than that of enalapril. In addition, concomitant administration of ivabradine and atenolol provides the best cardioprotective effects among pretreated groups with induced MI. Although the cardioprotective effects of the combination of ivabradine and enalapril on the \% of infarct size of the left ventricle were not significantly different from that of ivabradine denoting no significant interaction between the two drugs on this parameter, the combination demonstrated significant beneficial effects on many other studied parameters.

In the present work, the MABP was significantly decreased in the control MI group in comparison to both the basal value (before coronary artery ligation) and that of the sham-operated group. These findings are in accordance with those obtained by Liu $\boldsymbol{e t}$ al. ${ }^{[22]}$, which could be explained by development of cardiogenic shock or low cardiac output state associated with $\mathrm{MI}^{[23,24]}$.

In the present study, pretreatment of rats with ivabradine, atenolol, enalapril, ivabradine with atenolol and ivabradine with enalapril did not significantly reduce the MABP in comparison with their baseline values. This effect could be attributed the ability of these drugs to prevent the 
development of cardiogenic shock as evidenced in the present work by reduction of the infarct size $\%$ and the positive effect on all biochemical markers of myocardial injury. Similar findings were reported by Lewis et al. ${ }^{[25]}$, Post and Münzel ${ }^{[26]}$ and Zmudka et al. [27].

The present work reveals that there is no interaction between ivabradine and either atenolol or enalapril on the MABP. Similar results were demonstrated in previous studies by Koester et al. ${ }^{[28]}$ and Tardif et al. ${ }^{[29]}$.

In the present study, coronary artery ligation caused significant increase in HR of rats in the control MI group. Similar findings were reported by Heusch and Yoshimoto ${ }^{[30]}$ and Indolfi and Ross ${ }^{[31]}$. This could be attributed to the increased activity of the adrenergic system by MI which is reflected by raised plasma catecholamine concentration [32].

In the current study, ivabradine not only significantly decreased the HR before coronary artery ligation but also decreased tachycardia caused by MI. This could be explained by blocking of the $I_{\mathrm{f}}$ current which plays a role in spontaneous depolarization of the pacemaker cells ${ }^{[9]}$. As the increase of HR after MI could be attributed to the increased activity of the adrenergic system ${ }^{[32]}$ and as fchannels are directly gated by cAMP ${ }^{[12]}, \beta$ adrenergic stimulation increases cAMP concentration in pacemaker cells which results in increase of the $I_{\mathrm{f}}$ current and the slope of the diastolic depolarization which shortens the diastolic time and accelerates the HR. Therefore, direct inhibition of the $I_{\mathrm{f}}$ current by ivabradine appears to be an ideal target to induce a selective reduction of resting HR as well as of tachycardia mediated by an increase in sympathetic tone ${ }^{[33]}$.

The present finding that HR reduction by ivabradine was not significantly different from that of the atenolol agrees with that of Christensen et al. ${ }^{[34]}$ who demonstrated that treatment with ivabradine or atenolol reduced HR to identical degrees.

As regard the co-administration of ivabradine and atenolol, the results of the present study demonstrated significant HR reduction in comparison to the effect of each drug alone; indicating potentiating effect between the two drugs on the HR, which is in agreement with the results of Berdeaux ${ }^{[35]}$.

Concerning co-administration of ivabradine and enalapril, the results of the present study revealed no interaction between the two drugs on the HR; however, there is a lack of data concerning this interaction.

In the current study, both the ST height and $\mathrm{T}$-wave voltage significantly increased in the control MI group after coronary artery ligation. These findings are in accordance with the study by Wang et al. ${ }^{[36]}$.

The current study also showed significant elevations of serum levels of CK$\mathrm{MB}$, cTnI and hs-CRP of the control MI group. These findings are consistent with that obtained by de Zwaan et al. ${ }^{[37]}$, Ma et al. ${ }^{[38]}$ and Neri et al. ${ }^{[39]}$.

The results of the present study demonstrated that ST height and T-wave voltage in the ivabradine-pretreated group was significantly lower than that recorded in the control MI group. Also, serum levels of CK-MB, hs-CRP and cTnI and infarct size \% in this group were significantly lower than that of the control MI group. These results are consistent with that obtained by Dedkov $\boldsymbol{e t} \boldsymbol{a l}$. ${ }^{[40]}$, Dominguez-Rodriguez et al. ${ }^{[41]}$, Heusch et al. ${ }^{[42]}$, Monnet et al. ${ }^{[43]}$ and Vilaine et al. [44]. The mechanism of the cardioprotective effect of ivabradine could be self-explained in the present study by its significant HR reduction, significant decrease of the apoptotic factor Bax and significant increase of the antioxidant markers SOD\& GSH.

Fox et al. ${ }^{[45]}$ reported that HR reduction is considered as one of the main therapeutic targets in patients with ischemic heart diseases. Ceconi et al. ${ }^{[46]}$ mentioned that ivabradine by $\mathrm{HR}$ reduction, it improves coronary perfusion by increasing diastolic perfusion time, improves subendocardial perfusion and myocardial regional function during ischemia. In addition, it decreases myocardial oxygen consumption by reducing $\mathrm{HR}$ and ventricular wall stress. Ivabradine does not unmask $\alpha$-adrenergic coronary vasoconstriction in large epicardial arteries during sympathetic activation which 
preserves myocardial contractility and coronary vasodilatation during exercise ${ }^{[47,48]}$.

The present work demonstrated that atenolol provides better cardioprotective effects against acute $\mathrm{MI}$ than ivabradine regarding values of serum levels of CK-MB hs-CRP and cTnI and infarct size \% and these findings are in agreement with that of Colin et al. ${ }^{[47]}$. This may be attributed to the fact that atenolol produced simultaneous reduction of HR and contractility and thus reducing stroke volume and cardiac output when sympathetic tone increases ${ }^{[48]}$.

The present study demonstrated that in enalapril-pretreated group, the ST height, serum levels of CK-MB and cTnI and infarct size $\%$ were significantly higher than those of the ivabradine-pretreated group. These findings are agreed with that obtained by Halperin et al. ${ }^{[49]}$ and Prasad et al. ${ }^{[50]}$.

As regards ivabradine and atenololpretreated group, the results of the present study demonstrated that although the effect of this combination on ST height, T-wave voltage and serum levels of CK-MB and cTnI were significantly lower than that observed with ivabradine; it was not significantly different from that observed by the atenololpretreated group indicating that no interaction between ivabradine and atenolol on these parameters. The infarct size $\%$ observed with this combination was significantly lower than that of ivabradine-pretreated and atenololpretreated groups indicating potentiation between the two drugs on the infarct size.

These results are consistent with that obtained from previous other short-term experimental studies which demonstrated that ivabradine and $\beta$-blockers possess complementary and perhaps even additive pharmacological properties linked to their

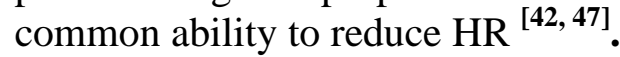

As regard the combined pretreatment with ivabradine and enalapril, the results of the present study demonstrated that ST height and $\mathrm{T}$-wave voltage were not significantly different from either ivabradine or enalapril demonstrating no interaction of the two drugs on these parameters. The serum levels of CK$\mathrm{MB}$ and $\mathrm{cTnI}$ in the in this group were significantly lower than those observed with groups pretreated by either ivabradine or enalapril indicating potentiation between the two drugs on these parameters. The infarct size $\%$ of the ivabradine and enalaprilpretreated group was not significantly different from either the ivabradine or enalapril group indicating no interaction on this parameter. However, no data could be found in the available literature concerning ivabradine-enalapril interaction.

The results of the current study demonstrated that rats of the control MI group show significant elevations of serum levels of NT-proBNP, this may be attributed to the production of NT-proBNP predominately by the cardiac ventricular myocytes at times of cardiac stress and damage ${ }^{[51]}$. The serum level of NT-proBNP in the ivabradinepretreated group was significantly lower than that of the control MI group. This is consistent with data obtained by Sarullo et al. ${ }^{[52]}$ and could be attributed to HR reduction by ivabradine reduces ventricular wall stress during ischemia ${ }^{[47]}$.

Also, the present study demonstrated that the serum level of NT-proBNP of rats pretreated with a combination of ivabradine and atenolol significantly lower than that determined in ivabradine-pretreated group. However, the effect of this combination was not significantly different from that observed with atenolol indicating no interaction between the two drugs in this marker. However, no data could be found in the available literatures concerning this effect.

The results of the present study demonstrated that the serum level of NTproBNP of rats pretreated with a combination of ivabradine and enalapril significantly lower than that determined with either ivabradine or enalapril. This may be the underlying basis of the potentiation between the two drugs in this parameter. However, there is a lack of data concerning this interaction.

In the present study, the SOD \& GSH activity of the control MI group was significantly lower than that of the shamoperated group. Sharma et al. ${ }^{[53]}$ reported that lower SOD activity might be due to an excessive formation of superoxide anions. Meister ${ }^{[54]}$ stated that GSH is one of the most 
abundant non-enzymatic antioxidant present in the body. Lil et al. ${ }^{[55]}$ reported that decreased GSH level may be due to its enhanced utilization for augmenting the activities of glutathione peroxidase (GPx). Panda et al. ${ }^{[56]}$ stated that endogenous antioxidants such as SOD and GPX are the first line of cellular defense enzymes against oxidative injury and are usually depleted in conditions associated with oxidative stress.

The results of the present study exhibited that tissue level of SOD \& GSH in the ivabradine-pretreated group were significantly higher than those of the control MI group which are in agreement with that obtained by Custodis et al. ${ }^{[57]}$. The antioxidant effect of ivabradine was explained by Custodis et al. [57] and Heusch and Kleinbongard ${ }^{[58]}$ as being due to decreased activity of reduced nicotinamide adenine dinucleotide phosphate (NADPH)-oxidase resulting from diminished mechanical shear stress by decreasing HR

The present study demonstrated that although the tissue level of SOD in rats pretreated with concomitant administration of ivabradine and atenolol was significantly higher than that of the ivabradine; it was not significantly different from that observed with atenolol denoting no interaction between the two drugs on this marker. On the other hand, the tissue level of GSH observed with this combination was significantly higher than that observed with either ivabradine or atenolol indicating potentiation between the two drugs on this parameter. However, there is a lack of data concerning this interaction.

The results of the present study demonstrated that the tissue levels of SOD \& GSH in the ivabradine and enalaprilpretreated group were significantly higher than that observed with enalapril; however it was not significantly different from that observed with ivabradine illustrating that there is no interaction between the two drugs on these markers. No data could be found in the available literatures concerning this effect.

The results of current study demonstrated that the tissue level of Bax (apoptosis factor) was significantly higher in the control MI group in comparison to the sham-operated group. This finding is in line with that obtained by Matsushita et al. ${ }^{[59]}$ and Miyashita et al. ${ }^{[60]}$ as they demonstrated that apoptosis was associated with a decrease in $\mathrm{Bcl}-2$ protein and an increase in the expression of Bax. Timmins et al. [61] mentioned that during $\mathrm{MI}$ the increased intracellular $\mathrm{Ca}^{2+}$ activates $\mathrm{CaMK}_{\text {II. }}$. Roe and Ren ${ }^{[62]}$ and Velez Rueda et al. ${ }^{[63]}$ stated that activated $\mathrm{CaMK}_{\mathrm{II}}$ has been linked to increased Bax expression, leading to apoptosis.

The results of the present study demonstrated that the tissue level of Bax in the ivabradine-pretreated group was significantly lower than that of the control MI group. This may be attributed to HR reduction and the consequent decrease in the $\mathrm{Ca}^{2+}$ overload. Vaillant et al. ${ }^{[64]}$ reported that ivabradine could limit cardiac alterations associated with tachycardia and ischemia/reperfusion. Yaniv et al. [65] reported that sarcoplasmic reticulum (SR) $\mathrm{Ca}^{2+}$ load is reduced and spontaneous local $\mathrm{Ca}^{2+}$ releases from SR via ryanodine receptors are suppressed with ivabradine.

The present study demonstrated that the tissue level of Bax in the group of rats pretreated with concomitant administration of ivabradine and atenolol was significantly lower than that of the ivabradine-pretreated groups. However, it was not significantly different from that observed with atenolol indicating no interaction of the combination on this marker. No data could be found in the available literatures concerning this effect.

The results of the present work demonstrated that the tissue level of Bax in the group of rats pretreated with combination of ivabradine and enalapril was significantly lower than that of either ivabradine or enalapril-pretreated groups; which demonstrate potentiation between the two drugs on this marker. No data could be found in the available literatures concerning this effect.

\section{CONCLUSION}

The present study demonstrated that ivabradine possesses cardioprotective effects against acute MI induced by persistent coronary artery ligation in rats as evidenced by significant decrease of each of the $\%$ of 
infarct size, ST height, T-wave voltage, CK$\mathrm{MB}$, cTnI, hs-CRP and NT-proBNP (the markers of cardiac stress and damage). The mechanism of the protective effect was demonstrated in the present work, at least in part, by decreasing the apoptotic factor Bax and increasing the activity of the antioxidant markers SOD \& GSH. This protective effect is lower than that of atenolol; but higher than that of enalapril. In the atenolol-pretreated group, serum levels of CK-MB, cTnI, hs-CRP and NT-proBNP, tissue level of Bax and infarct size \% were significantly lower than those of the ivabradine-pretreated group; also, tissue levels of SOD \& GSH in animals pretreated with atenolol were significantly higher than that of the ivabradine-pretreated group.

Serum levels of CK-MB, cTnI, hs-CRP and NT-proBNP, tissue level of Bax and infarct size $\%$ of the enalapril-pretreated group were significantly higher than those of the ivabradine-pretreated group; also, tissue levels of SOD in animals pretreated with enalapril were significantly lower than that of the ivabradine-pretreated group.

In addition, concomitant administration of ivabradine and atenolol provides the best cardioprotective effect among pretreated groups as both drugs potentiate each other against ischemic insult. Although the combination of ivabradine and enalapril on the $\%$ of infarct size was not significantly different from that of ivabradine, they potentiate each other on serum levels of CKMB, cTnI, hs-CRP and NT-proBNP and tissue level of Bax.

From the results of the present study it could be recommended that the use of ivabradine in acute MI may be a good alternative to $\beta$-adrenoceptor blockers when these drugs are contraindicated. In addition, the use of combinations of ivabradine with $\beta$ adrenoceptor blockers or enalapril in acute MI may be recommended. However, further experimental and clinical studies are needed to confirm these findings.

\section{Abbreviations}

ACS: acute coronary syndrome; b/m: beats per minute; Bax: Bcl-2-associated $\mathrm{X}$ protein; $\mathbf{C a M K}_{\mathrm{II}}$ : $\mathrm{Ca}^{2+} /$ calmodulin-activated protein kinase II; CAD: coronary artery disease; CK-MB: Creatine Kinase MB isoenzyme; cTnI: Cardiac Troponin-I; CVD: cardiovascular disease; ECG: electrocardiogram; ELISA: enzyme-linked immunosorbent assay; GSH: reduced glutathione; GPx: glutathione peroxidase; HF: heart failure; HR: heart rate; hs-CRP: high-sensitivity C-reactive protein; MABP: mean arterial blood pressure; MI: myocardial infarction; NADPH: reduced nicotinamide adenine dinucleotide phosphate; NTproBNP: N-terminal pro-brain-type natriuretic peptide; SE: standard error of mean; SOD: superoxide dismutase; TTC: Triphenyl-Tetrazolium Chloride.

\section{REFERENCES}

1) Mozaffarian D, Benjamin EJ, Go AS, Arnett DK, Blaha MJ, Cushman M, et al. Heart Disease and Stroke Statistics-2016 Update: A Report From the American Heart Association-Chapter 13. Circulation 2016; 133(4): $38-360$.

2) Thygesen K, Alpert JS, Jaffe AS, Simoons ML, Chaitman BR, White HD, et al. Third universal definition of myocardial infarction. Circulation, 2012; 126(16):2020-2035.

3) Fox K, Ferrari R, Tendera M, Steg PG, and Ford I. Rationale and design of a randomized, doubleblind, placebo-controlled trial of ivabradine in patients with stable coronary artery disease and left ventricular systolic dysfunction: the morBiditymortality EvAlUaTion of the I(f) inhibitor ivabradine in patients with coronary disease and leFt ventricULar dysfunction (BEAUTIFUL) study. Am Heart J., 2006; 152:860-866.

4) Ferrari $\mathbf{R}$ and Ceconi C. Selective and specific $I_{\mathrm{f}}$ inhibition with ivabradine: new perspectives for the treatment of cardiovascular disease. Expert Rev Cardiovasc Ther., 2011; 9(8): 959-973.

5) Reil JC, Custodis F, Swedberg K, Komajda M, Borer JS, Ford I, et al. Heart rate reduction in cardiovascular disease and therapy. Clin Res Cardiol., 2011; 100(1):11-19.

6) Werdan K, Ebelt H, Nuding S, Höpfner F, Hack $G$, and Müller-Werdan $U$. Ivabradine in combination with beta-blocker improves symptoms and quality of life in patients with stable angina pectoris: results from the ADDITIONS study. Clin Res Cardiol., 2012; 101(5):365-373.

7) Montalescot G, Sechtem U, Achenbach S, Andreotti F, Arden C, Budaj A, et al. 2013 ESC guidelines on the management of stable coronary artery disease: the task force on the management of stable coronary artery disease of the European Society of Cardiology. Eur Heart J., 2013; 34(38):2949-3003.

8) Ferrari R, Cargnoni A, and Ceconi C. Antiischemic effect of ivabradine. Pharmacol Res., 2006; 53(5):435-439.

9) DiFrancesco D. The role of the funny current in pacemaker activity. Circ Res., 2010; 106(3):434-446.

10)Savelieva I, and Cam AJ. $I_{f}$ inhibition with ivabradine: electrophysiological effects and safety. Drug Saf., 2008; 31(2):95-107.

11) Fasullo S, Cannizzaro $S$, Maringhini G, Ganci $F$, Giambanco F, Vitale G, et al. Comparison of 
ivabradine versus metoprolol in early phases of reperfused anterior myocardial infarction with impaired left ventricular function: preliminary findings. J Card Fail., 2009; 15(10):856-863.

12) Custodis F, Reil JC, Laufs U, and Böhm M. Heart rate: a global target for cardiovascular disease and therapy along the cardiovascular disease continuum. J Cardiol., 2013; 62(3):183-187.

13) Maczewski M, and Mackiewicz U. Effect of metoprolol and ivabradine on left ventricular remodelling and $\mathrm{Ca}^{2+}$ handling in the post-infarction rat heart. Cardiovasc Res., 2008; 79(1):42-51.

14)Gould S, Westwood FR, Curwen JO, Ashton SE, Roberts DW, Lovick SC, et al. Effect of pretreatment with atenolol and nifedipine on ZD6126-induced cardiac toxicity in rats. J Natl Cancer Inst., 2007; 99(22): 1724-1728.

15) Richer C, Fornes $P$, Domergue V, De Gasparo $M$, and Giudicell JF. Combined angiotensin II $\mathrm{AT}_{1^{-}}$ receptor blockade and angiotensin I-converting enzyme inhibition on survival and cardiac remodeling in chronic heart failure in rats. J Card Fail., 2001; 7(3):269-276.

16) Iwamoto $K$, Watanabe $J$, and Atsumi $F$. Effects of urethane anesthesia and age on organ blood flow in rats measured by hydrogen gas clearance method. $J$ Pharmacobiodyn., 1987; 10(6):280-284.

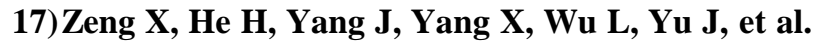
Temporal effect of Guanxin No. 2 on cardiac function, blood viscosity, and angiogenesis in rats after long-term occlusion of the left anterior descending coronary artery. J Ethnopharmacol., 2008; 118(3): 485-494.

18) Fishbein MC, Meerbaum S, Rit J, Londo U, Kanmatsuse K, Mercier JC, et al. Early phase acute myocardial infarct size quantification: validation of the triphenyl tetrazolium chloride tissue enzyme staining technique. Am Heart J., 1981; 101(5):593600.

19) Baltogiannis GG, Tsalikakis DG, Mitsi, AC, Hatzistergos KE, Elaiopoulos D, Fotiadis DI, et al. Endothelin receptor-A blockade decreases ventricular arrhythmias after myocardial infarction in rats. Cardiovasc Res., 2005; 67(4):647-654.

20) Maczewski $M$ and Mackiewicz U. Plasma brain natriuretic peptide correlates with infarct size but not with subsequent remodeling in the rat heart. Cardiovasc Pathol., 2007; 16(2):79-84.

21)Armitage $\mathbf{P}$ and Berry G. Statistical methods in medical research, $3^{\text {rd }}$ edition; Blackwell Scientific Publications, Oxford. London. 1994; pp 620.

22)Liu YH, Yang XP, Sharov VG, Sigmon DH, Sabbath HN, and Carretero OA. Paracrine system in the cardioprotective effect of angiotensinconverting enzyme inhibitors on myocardial ischemia/reperfusion injury in rats. Hypertension, 1996; 27(1):7-13.

23) Agress CM, Glassner HF, Binder MJ, and Fields J. Hemodynamic measurements in experimental coronary shock. J Appl Physiol., 1957; 10(3):469475 .
24)Stenberg TA, Kildal AB, Sanden E, How OJ, Hagve M, Hagve M, et al. The Acute Phase of Experimental Cardiogenic Shock Is Counteracted by Microcirculatory and Mitochondrial Adaptations. PLoS ONE, 2014; 9(9): e105213, 8 pages.

25)Lewis RA, Baker KM, Ayers CR, Weaver BA, and Lehman MR. Captopril versus enalapril maleate: a comparison of antihypertensive and hormonal effects. J Cardiovasc Pharmacol., 1985; 7(Suppl1):S12-S15.

26) Post $F$ and Münzel $T$. Ivabradine-A new therapeutic option for cardiogenic shock? Herz. 2009; 34(3):224-229.

27)Zmudka K, Dubiel J, Vanhaecke J, Flameng W, and de Geest $\mathbf{H}$. Effects of oral pretreatment with metoprolol on left ventricular wall motion, infarct size, hemodynamics, and regional myocardial blood flow in anesthetized dogs during thrombotic coronary artery occlusion and reperfusion. Cardiovasc Drugs Ther., 1994; 8(3):479-487.

28)Koester R, Kaehler J, Ebelt H, Soeffker G, Werdan K, and Meinertz T. Ivabradine in combination with beta-blocker therapy for the treatment of stable angina pectoris in every day clinical practice. Clin Res Cardiol., 2010; 99(10):665-672.

29) Tardif JC, Ford I, Tendera M, Bourassa MG, and Fox K; INITIATIVE Investigators. Efficacy of ivabradine, a new selective I(f) inhibitor, compared with atenolol in patients with chronic stable angina. Eur Heart J., 2005; 26(23):2529-2536.

30) Heusch $\mathbf{G}$ and Yoshimoto N. Effects of heart rate and perfusion pressure on segmental coronary resistances and collateral perfusion. Pflügers Arch., 1983; 397(4):284-289.

31)Indolfi $\mathbf{C}$ and Ross $\mathbf{J}$ Jr. The role of heart rate in myocardial ischemia and infarction: implications of myocardial perfusion-contraction matching. Prog Cardiovasc Dis., 1993; 36(1):61-74.

32) Januszewicz W, Sznajderman M, Sznajderman C, Wocial B, and Rymaszewski Z. Plasma free fatty acid and catecholamine levels in patients with acute myocardial infarction. Brit Heart J., 1971; 33(5):716-718.

33) Vilaine JP. The discovery of the selective If current inhibitor ivabradine A new therapeutic approach to ischemic heart disease. Pharmacol Res., 2006; 53(5):424-434.

34) Christensen LP, Zhang R, Zheng W, Campanelli JJ, Dedkov EI, Weiss RM, et al. Postmyocardial infarction remodeling and coronary reserve: effects of ivabradine and beta blockade therapy. Am J Physiol Heart Circ Physiol., 2009; 297(1): H322-H330.

35) Berdeaux A. Ivabradine (Procoralan) alone or with $\beta$-blockers in myocardial ischemia. Heart Metab., 2010; 47(1):30-33.

36) Wang H, Cao C, Hui L, Liu T, Wang Y, Gao S, et al. A study of myocardial ischemia model induced by left coronary artery ligation in rats. World Journal of Cardiovascular Diseases 2016; 6(5):133-142.

37)de Zwaan C, Daemen MJ, and Hermens WT. Mechanisms of cell death in acute myocardial 
infarction: pathophysiological implications for treatment. Neth Heart J., 2001; 9(1):30-44.

38) Ma X, Zhang K, Li H, Han S, Ma Z, and Tu P. Extracts from Astragalus membranaceus limit myocardial cell death and improve cardiac function in a rat model of myocardial ischemia. $J$ Ethnopharmacol., 2013; 149(3):720-728.

39) Neri M, Fineschi V, Di Paolo M, Pomara C, Riezzo I, Turillazzi E, et al. Cardiac oxidative stress and inflammatory cytokines response after myocardial infarction. Curr Vasc Pharmacol., 2015; 13(1):26-36.

40)Dedkov EI, Zheng W, Christensen LP, Weiss RM, Mahlberg-Gaudin F, and Tomanek RJ. Preservation of coronary reserve by ivabradineinduced reduction in heart rate in infarcted rats is associated with decrease in perivascular collagen. Am J Physiol Heart Circ Physiol., 2007; 293(1):H590598.

41) Dominguez-Rodriguez A, Consuegra-Sanchez L, Blanco-Palacios G, Abreu-Gonzalez P, SanchezGrande A, Bosa-Ojeda F, et al. Anti-inflammatory effects of ivabradine in patients with acute coronary syndrome: a pilot study. Int J Cardiol., 2012; 158(1): 160-162.

42)Heusch G, Skyschally A, Gres P, van Caster P, Schilawa D, and Schulz R. Improvement of regional myocardial blood flow and function and reduction of infarct size with ivabradine: protection beyond heart rate reduction. Eur Heart J., 2008; 29(18): 22652275.

43) Monnet $X$, Colin $P$, Ghaleh $B$, Hittinger $L$, Giudicelli JF, and Berdeaux A. Heart rate reduction during exercise-induced myocardial ischaemia and stunning. Eur Heart J., 2004; 25(7):579-586.

44) Vilaine JP, Bidouard JP, Lesage L, Reure H, and Péglion JL. Anti-ischemic effects of ivabradine, a selective heart rate-reducing agent, in exerciseinduced myocardial ischemia in pigs. $J$ Cardiovasc Pharmacol., 2003; 42(5):688-696.

45)Fox K, Ford I, Steg PG, Tendera M, Robertson M, and Ferrari R; BEAUTIFUL investigators. Heart rate as a prognostic risk factor in patients with coronary artery disease and left-ventricular systolic dysfunction (BEAUTIFUL): a subgroup analysis of a randomised controlled trial. Lancet, 2008; 372(9641):817-821.

46) Ceconi C, Cargnoni A, Francolini G, Parinello G, and Ferrari R. Heart rate reduction with ivabradine improves energy metabolism and mechanical function of isolated ischaemic rabbit heart. Cardiovasc Res., 2009; 84(1):72-82.

47) Colin P, Ghaleh B, Monnet $X$, Su J, Hittinger L, Giudicelli JF, et al. Contributions of heart rate and contractility to myocardial oxygen balance during exercise. Am J Physiol Heart Circ Physiol., 2003; 284(2):H676-H682.

48) Simon L, Ghaleh B, Puybasset L, Giudicelli JF, and Berdeaux A. Coronary and hemodynamic effects of S 16257, a new bradycardic agent, in resting and exercising conscious dogs. J Pharmacol Exp Ther., 1995; 275(2):659-666.
49)Halperin JL, Faxon DP, Creager MA, Bass TA, Melidossian CD, Gavras H, et al. Coronary hemodynamic effects of angiotensin inhibition by captopril and teprotide in patients with congestive heart failure. Am J Cardiol., 1982; 50(5):967-972.

50) Prasad A, Mincemoyer R, and Quyyumi AA. Antiischemic effects of angiotensin-converting enzyme inhibition in hypertension. J Am Coll Cardiol., 2001; 38(4):1116-1122.

51) Maeda $K$, Tsutamoto $T$, Wada $A$, Hisanaga $T$, and Kinoshita M. Plasma brain natriuretic peptide as a biochemical marker of high left ventricular enddiastolic pressure in patients with symptomatic left ventricular dysfunction. Am Heart J., 1998; 135(5Pt1):825-832.

52)Sarullo FM, Fazio G, Puccio D, Fasullo S, Paterna S, Novo S, et al. Impact of "off-label" use of ivabradine on exercise capacity, gas exchange, functional class, quality of life, and neurohormonal modulation in patients with ischemic chronic heart failure. J Cardiovasc Pharmacol Ther., 2010; 15(4):349-355.

53)Sharma M, Kishore K, Gupta SK, Joshi S, and Arya DS. Cardioprotective potential of Ocimum sanctum in isoproterenol induced myocardial infarction in rats. Mol Cell Biochem., 2001; 225(1):75-83.

54) Meister A. New aspects of glutathione biochemistry and transport--selective alterations of glutathione metabolism. Nutr Rev., 1984; 42(12):397-410.

55)Lil JL, Stantman FW, and Lardy HA. Antioxidant enzyme systems in rat liver and skeletal muscle. Influences of selenium deficiency, chronic training, and acute exercise. Arch Biochem Biophys., 1988; 263(1): 150-160.

56) Panda $S$, Kar A, Banerjee $T$, and Sharma $N$. Combined effects of quercetin and atenolol in reducing isoproterenol-induced cardiotoxicity in rats: possible mediation through scavenging free radicals. Cardiovasc Toxicol., 2012; 12(3):235-242.

57)Custodis F, Baumhäkel M, Schlimmer N, List F, Gensch C, Böhm M, et al. Heart rate reduction by ivabradine reduces oxidative stress, improves endothelial function, and prevents atherosclerosis in apolipoprotein E-deficient mice. Circulation, 2008; 117(18): 2377-2387.

58)Heusch G, and Kleinbongard P.: Ivabradine: cardioprotection by and beyond heart rate reduction. Drugs 2016; 76(7):733-740.

59) Matsushita $K$, Umezawa A, Iwanaga $S$, Oda T, Okita H, Kimura K, et al. The EAT/mcl-1 gene, an inhibitor of apoptosis, is up-regulated in the early stage of acute myocardial infarction. Biochim Biophys Acta., 1999; 1472(3):471-478.

60) Miyashita T, Krajewski S, Krajewska M, Wang HG, Lin HK, Liebermann DA, et al. Tumor suppressor p53 is a regulator of bcl-2 and bax gene expression in vitro and in vivo. Oncogene, 1994; 9(6): 1799-1805.

61) Timmins JM, Ozcan L, Seimon TA, Li G, Malagelada C, Backs J, et al. Calcium/ calmodulindependent protein kinase II links ER stress with Fas 
and mitochondrial apoptosis pathways. J Clin Invest., 2009; 119(10):2925-2941.

62) Roe ND and Ren J. Oxidative activation of $\mathrm{Ca}(2+) /$ calmodulin-activated kinase II mediates ER stress-induced cardiac dysfunction and apoptosis. Am J Physiol Heart Circ Physiol., 2013; 304(6):H828839.

63) Velez Rueda JO, Palomeque J, and Mattiazzi A. Early apoptosis in different models of cardiac hypertrophy induced by high renin-angiotensin system activity involves CaMKII. J Appl Physiol., 2012; 112(12):2110-2120.
64) Vaillant F, Dehinaa L, Mazzadib A, Descotesc J, Chevalierd P, Tabibe $\mathbf{A}$, et al. Heart rate reduction with ivabradine increases ischaemia-induced ventricular fibrillation threshold: Role of myocyte structure and myocardial perfusion. Resuscitation, 2011; 82(8): 1092-1099.

65) Yaniv Y, Sirenko S, Ziman BD, Spurgeon HA, Maltsev VA, and Lakatta EG. New evidence for coupled clock regulation of the normal automaticity of sinoatrial nodal pacemaker cells: bradycardic effects of ivabradine are linked to suppression of intracellular $\mathrm{Ca}^{2+}$ cycling. J Mol Cell Cardiol., 2013; 62:80-89. 